\title{
Educación, cuerpo y alteridad. Encuentros cara a cara para la formación del otro
}

\section{Education, body and alterity Meetings face to face for the formation of the other}

\begin{abstract}
Jhon Fredy Orrego Noreña es Docente-Investigador de la Maestría en Educación y Desarrollo Humano del Centro de Estudios Avanzados en Niñez y Juventud de la Universidad de Manizales y CINDE (Colombia) (jforrego@cinde.org.co) (https://orcid.org/0000-0002-4914-5636)
\end{abstract}

Diego Armando Jaramillo Ocampo es profesor de la Maestría en Pedagogía de la Universidad Católica de Manizales (Colombia) (djaramillo@ucm.edu.co) (https://orcid.org/0000-0002-3949-7697)

Recibido: 2018-04-15 / Revisado: 2018-11-05 / Aceptado: 2018-11-08 / Publicado: 2019-01-01

\section{Resumen}

No es posible pensar, reflexionar, hacer y/o transformar la educación al margen de la relación con el Otro; no se puede asumir la educación sin la pretensión de "formar" al Otro o por lo menos, intentarlo, como si tal cosa fuese posible. La educación, al igual que una práctica de transmisión de conocimiento (es también transmisión de cultura, lenguajes, modos y formas de ser y de estar, de nombrar y ser nombrado), pero, sobre todo, es un escenario de encuentro con el Otro, el cual dependerá de la concepción de sujeto y de mundo que se tenga, el desarrollo de una apuesta formativa. Este encuentro implica una transformación, ruptura, excedencia del sujeto de una ontología que encadena al sujeto a un utilitarismo cruel, para ir más allá, a un escenario en el que el sujeto ya no se encuentra solo a sí-mismo, sino que se encuentra con Otro, radicalmente diferente de él. Allí, es posible una educación que supere la preminencia del conocimiento y parta de una relación con el Otro. Dicha perspectiva, abordada desde las propuestas de los Filósofo Emmanuel Levinas y Joan Carles Mèlich, puede transitar por una educación moral centrada en el conocimiento, reglas y valores socialmente aceptados hasta una educación ética puesta sobre las necesidades formativas de los sujetos que responden responsablemente al y del Otro.

Descriptores: Educación, alteridad, ética, responsabilidad, acogimiento y cuerpo.

\footnotetext{
Abstract

Cannot possible think, do and / or transform education out of the relationship with the Other; you cannot assume education without the pretense of "form"
}

Forma sugerida de citar: Orrego Noreña, J. F., \& Jaramillo Ocampo, D. A. (2019). Educación, cuerpo y alteridad. Encuentros cara a cara para la formación del otro. Alteridad, 14(1), 89-97. https://doi.org/10.17163/alt.v14n1.2019.07 
the Other or at least try, as if such a thing were possible. Education, as a practical transmission of knowledge (also transmission of culture, languages, ways and ways of being and living, to appoint and be appointed), but above all, is a scene of encounter with the Other, which depend on the conception of the subject and the world you have, the development of a training bet. This encounter implies a transformation, rupture, leave of the subject of an ontology that chains the subject to a cruel utilitarianism, to go further, to a scenario in which the subject no longer finds himself alone, but finds himself with Other, radically differ-

\section{Introducción}

Durante el proceso de formación emergen gran cantidad de preguntas, interrogantes que van de un lado para el otro, de aquí para allá, cuestionamientos que transitan por las clases, los seminarios; incertidumbres que se sacuden en los pasillos y las cafeterías de las instituciones educativas y dudas que traspasan las diferentes clases y asignaturas que hacen presencia en el proceso formativo. Para el campo de la educación, estas preguntas están dirigidas en general sobre ¿Qué es la pedagogía? ¿Cuáles son las corrientes en las que se enfocan sus propuestas? ¿Cuáles son los modelos más apropiados para atender las múltiples realidades de nuestro país? ¿Qué papel juega la didáctica en la organización de los ambientes educativos? ¿Cuáles son los saberes más pertinentes y en qué lugar del proceso de formación se pueden ubicar? ¿Cómo transformar la realidad educativa? Entre tantas otras.

Todas estas preguntas que permiten proponer los diferentes encuentros en el campo de la educación no alcanzan a abarcar (o por lo menos no de manera explícita), otras cuestiones de igual o mayor importancia en la comprensión y transformación de la educación, como por ejemplo: ¿Qué es la educación? ¿Cuáles son sus trazos y horizontes de formación en el otro o con el Otro'? ¿Es posible pensarla al margen del sujeto? ¿Cuáles son las relaciones que se construyen en el marco de su práctica? ¿Debe la educación formar o, más bien, posibilitar la formación del Otro? ¿Quién ent from him. There, an education that exceeds the preeminence of knowledge and starts from a relationship with the Other is possible. This perspective, addressed from the proposals of the philosopher Emmanuel Levinas and Joan Carles Mèlich, can pass through a moral education based on knowledge, rules and socially accepted to a putting on the training needs of individuals who respond responsibly to education and other ethical values.

Keywords: Education, alterity, ethics, responsibility, fostering, body.

es el Otro de la educación? ¿Cómo se asume la existencia del Otro en los procesos de formación? ¿Hacia dónde se enfoca la relación que se establece con el Otro? ¿Cuáles son las condiciones de posibilidad para que la educabilidad aparezca y el Otro sea un sujeto educable? ¿Existe alguna diferencia entre hablar del otro o hablar con el Otro en educación²?; estas y muchas otras preguntas deberían dirigir permanentemente la labor educativa, orientar sus reflexiones, dinamizar sus procesos de cambio y transformación social de las personas y de las instituciones (Murcia, 2012).

Estos asuntos emergen permanentemente en el marco de escenarios contemporáneos, escenarios impregnados tanto de hegemonías y poderes como de resistencias y rupturas, en los cuales se exige cada vez más la re-significación de la educación, de la escuela, del conocimiento y de los saberes que por ella transitan en busca de superar escenarios tradicionales que han reducido al sujeto educable a un ser "cansado (...) una sociedad que se caracteriza por la desaparición de la otredad y la extrañeza" (Chul Han, 2012, p. 8 ), una sociedad que ve en el otro, en su ser, en su cuerpo, la diferencia que separa bien sea para excluir y rechazar o para incluir y normalizar, como si este no tuviese algo que enseñar, algo que decir, algo que mostrar, algo que contar, algo para dar.

Estas sociedades "cansadas" y "agotadas" por la velocidad del mundo "moderno", cada vez encierran más a las personas en su mismidad, es decir, cada vez se interacciona y se está más 
informado con el mundo al tiempo que se deja de conversar, compartir y conocer con los otros, pues la racionalidad moderna asume la cantidad y el ruido como opción de comunicación con los otros; sin embargo, se hace necesario una salida del terreno del ser que implique pensar y ser de otro modo (Lévinas, 1987), una pausa, un silencio, una paz que permita mirar y escuchar al Otro sin prejuicio y que le dé al sujeto una distancia en la que la alteridad radical no quede subsumida en los poderes del yo. Esto podría impedir "que el otro se cosifique como un objeto, como un 'ello'..." (Chul Han, 2014, p. 13).

Todo un desafío emerge en estos tiempos de premura y ocupación, este cansancio, esta cosificación y esta negación del Otro no se han limitado a la vigilancia y el control sobre las prácticas que podemos o no realizar, aprender e incluso pensar; se ha legitimado también en y sobre el cuerpo toda una estructura de dominación y encierro del cuerpo como totalidad (Lévinas, 1977, 2012).

Sin embargo, el cuerpo escapa cualquier intento o pretensión de captura y clasificación. Desde esta perspectiva, el ser humano que se muestra o que se "da" en su condición frágil y vulnerable lo hace desde su condición finita, tal como lo plantea Mèlich (2010b), para quien:

Los seres humanos somos corpóreos. Nuestra condición no es 'corporal' sino 'corpórea'. La corporeidad provoca una fractura, una grieta en nuestra identidad. Somos corpóreos porque no empezamos de cero, porque nacemos en un universo simbólico, en una gramática, y, al mismo tiempo, no estamos ubicados del todo, terminados del todo, constituidos del todo. Somos seres por hacer o haciéndonos (p. 37).

Esta ubicación de la condición de humanidad desde el cuerpo y en el cuerpo, lleva a pensar que los procesos de relación y encuentro son mucho más que asistir pasivamente a recibir una clase de manera tradicional y rutinaria, implican la constitución de la subjetividad por la irrup- ción del Otro, del cuerpo "que es el Otro", de su humanidad en la relación educativa.

Precisamente, la educación y la escuela tal como se conciben hoy en día, se han convertido en tiempos y espacios para adoctrinar, donde el único actor "activo" es un conocimiento impuesto que ha excluido los sujetos y los ha dejado en sus márgenes, y es justo allí fuera de la escuela donde otras formas de educación han emergido, acogiendo al ser humano, procurando su humanidad, otorgando reconocimiento a su condición sintiente, corpórea, dando un lugar transformador para sí mismo y para el contexto que lo rodea.

Es por ello, que pensar la relación entre educación, cuerpo y alteridad cobra valor, pues la educación debe recuperar su lugar como escenario de encuentro entre sujetos, encuentros que ocurren en un ser humano existente (Lévinas, 2006), de carne y hueso, finito, provisional, contingente (Mèlich, 2002, 2010a, 2010b) que también está ávido de saber, de experiencias que le permitan formarse a sí mismo en principio y desde allí aportar a la formación del Otro y de los otros; la educación y la escuela entonces deben volver la "mirada" y despertar su capacidad de "escucha" sobre su responsabilidad ética y política con la sociedad.

En estas consideraciones, desde una perspectiva ética, el proceso educativo se teje desde cuestionamientos tales como: ¿cómo se forma el ser humano? ¿cómo se aproxima al Otro en tanto Otro? y ¿qué relaciones se establecen con él en los múltiples espacios de encuentro que se constituyen como educativos?

En este sentido, abordar una apuesta por una educación desde/para/en y con la alteridad, podría asumirse como una redundancia pues todo proceso educativo siempre ha de estar dirigido hacia la formación del Otro, un Otro que demanda la presencia y la voz de un interlocutor, otro con el "quien" explorar el mundo (incluso el mundo del saber y el conocimiento) para con él reconstruirlo permanentemente; Otro que es corporeidad para sí 
y para el Otro, que mediante ella transita día a día en los escenarios de la vida humana.

\section{Desde el sujeto a la alteridad}

La alteridad, no es una condición que se dé per-se o se pueda definir, es precisamente lo indefinible en el ser humano, ${ }^{3}$ lo que no se puede enmarcar bajo ninguna categoría o nombrar de alguna manera, la alteridad es lo inefable en el sujeto y escapa a cualquier marco de referencia social y/o cultural.

De esta manera, si bien la alteridad es lo innombrable en el Otro, esta sólo puede emerger en la relación con él, esto implica que alguien (sea yo, o sea el Otro) se desprende de sus escudos, del mundo o la gramática ${ }^{4}$ la cual lo define o lo está definiendo, asumirse curioso y contemplativo frente a lo extraño, frente al rostro del Otro que se presenta como epifanía es lo que hace posible que la respuesta sea hospitalaria y fraterna, una respuesta cálida para acogerlo y hacerse responsable de él, de su singularidad antes que él mismo me exija cualquier responsabilidad (una responsabilidad sin justificación alguna y sin ningún porqués).

De igual manera, llegar hasta el Otro, hasta el infinito, ${ }^{6}$ es un camino arduo que implica una transformación del sí-mismo, una liberación de sí para poder trascender al Otro, librar una lucha constante con nuestra identidad, desprotegernos, distanciarnos de los marcos morales para ir en busca de lo ético, abrirnos a lo que aún no es y no sabemos si será.

Esta liberación parte de asumirnos, en primera instancia, como seres encadenados al mundo, encadenados a la existencia, encerrados en una consciencia tan particular que nos aísla de los demás, aun cuando compartimos un mundo con ellos, incluso estos, los otros, son vistos como "objetos" puestos allí, junto a mí, pero que no me afectan directamente, sino que desde la definición de sus características busco controlar, nombrar, clasificar, tematizar, ello para distinguir otros "objetos" en el mundo y saber cómo relacionarme y dirigirme hacia ellos.
La relación con ese mundo y los objetos es una relación moral, es una gramática ${ }^{7}$ del mundo, en la cual encontramos todo los insumos para dirigirnos a él de manera predeterminada. En esta relación, las respuestas ante todas las preguntas ya están dadas, ya se han definido por quienes creen tener la "razón" o la "verdad", por aquellos que legitiman su poder y su crueldad tanto en lo que dicen como en lo que hacen, lo cual hace que todo deje de ser extraño y novedoso para ser "normal", en ese instante todo se ha "naturalizado" y nada sorprende, pero tampoco, nadie interrumpe.

La gramática, es el escudo ante la paranoia producida por la diferencia, ante lo incontrolable, ante lo efímero; la gramática es así la normalización del mundo, para sentirnos seguros creyendo que "todo está bajo control" tan sólo por ser capaz de nombrarlo dentro de nuestros marcos referenciales.

Así, el Otro es otro, en tanto objeto a la consciencia, es otro representado, dibujado, clasificado y limitado a mi gama de posibilidades de nombrar sus características, éste sujeto pierde así su particularidad y se vincula, incluye ${ }^{8}$ si se quiere, a un todo. Allí, nos encontramos con una cara, con ciertas características (ojos, boca, nariz, colores, formas) que requieren ser nombradas, pero que no dan cuenta de lo que en realidad es ese otro frente a mí, o sea, se convierte en un otro distante de mí y no próximo. ${ }^{9}$

No obstante, en el ser humano se genera un malestar ante las categorías en las cuales ha sido enmarcado, pues su nombre, ser alto o bajito, lindo, feo, blanco, negro, mestizo, hombre, mujer, niño, joven o adulto, etc., no logran dar cuenta de lo que en realidad él siente que es, pero que de igual manera, no encuentra en sus marcos de referencia formas de nombrarse, no encuentra en lo que se le ha impuesto como "ser". Este malestar Lévinas (2011) lo denomina como "náusea", como esa presión que se siente en el interior, desde el encierro en el cual ha sido puesto y que ya no basta para contenerlo, generando así una "necesidad ${ }^{10}$ de evasión", necesidad de salir de 
ese molde que le ha sido impuesto, ir más allá del sí-mismo para ser-Otro, para dar testimonio de sí a través de su propio lenguaje.

Este estrés genera rupturas en el sujeto, en sus formas de ver y dirigirse hacia el mundo que lo rodea, se moviliza, se desestabiliza, se sacude para agrietarse y poder "excederse", lograr salir de sí mismo, adentrarse en la oscuridad, alejarse de la luz que le ha marcado el rumbo y caminar en la incertidumbre hacia lo imprevisto en busca de nuevos horizontes, caminar sin rumbo fijo.

Esta excedencia se da a través de un lenguaje propio, de una forma particular de decirse, de dar testimonio de sí encontrando sus propias palabras, descubriendo otras; otro lenguaje que fluye hacia el exterior en busca del Otro-ser excedido también de sí mismo, en busca de la alteridad. Pero este lenguaje propio, demanda del Otro su presencia para ser escuchado, para ser contemplado, para que lo encuentre y lo acoja, por eso ir hacia el Otro es excederse, esto requiere del deseo por él o ella -pero no un deseo como necesidad de algo que nos falta y podemos obtener, sino- como deseo de lo inalcanzable, deseo de un horizonte que nos convoca pero que no podemos alcanzar.

Dicho así, el Otro, la humanidad, el infinito (para Lévinas), es quien nos llama y exige nuestra atención, escucha, contemplación; su rostro trasciende las características nombrables de la cara y se presenta como lenguaje, como epifanía, presenta su dolor, su pasión, su emoción, su demanda, su alegría y su sufrimiento.

Este encuentro con el Otro (entre otros) que se presenta cada quien desde sus lenguajes, implica escucha atenta, contemplación, responsabilidad (compasión diría Mèlich, 2010b) por el otro, responder a su demanda, incluso en ausencia de un llamado explícito. Apenas acá, luego de las rupturas con uno mismo logramos encontrarlo al aproximarnos a él sin abarcarlo, sin controlarlo ni clasificarlo, justo acá asistimos, frente al rostro del Otro, a su epifanía, al encuentro ético, a la relación educativa que responde responsablemente por el Otro.

\section{De la educación moral al encuentro ético}

Plantea Joan-Carles Mèlich que toda educación es moral, en tanto la educación es el proceso a través del cual heredamos la cultura, las normas, las leyes, los comportamientos, incluso, las formas de pensar y hasta de sentir. En este sentido, la educación es una educación gramatical, pues aprendemos a nombrar, clasificar, incluir y excluir todo lo que nos rodea, incluso a los otros. Una educación moral, no tiene como preocupación central al sujeto, sino al conocimiento, toda vez que el primero es también conocimiento, es un cúmulo de características de las cuales podemos dar cuenta a partir de marcos referenciales heredados social y culturalmente. Desde este punto de vista, educar al ser humano implica llenarlo de conocimientos ${ }^{11}$ desde los cuales dar cuenta de todo a su alrededor, es enseñarle a protegerse de la incertidumbre, es decir, enseña a no ponerse frente al Otro sino a espaldas de él y esperar que los marcos morales predeterminados de la sociedad lo incluyan o lo excluyan y desde allí, desde la periferia, actuar en favor o en contra de él.

La educación vista desde este punto de vista, se ha convertido en un escenario de transmisión de conocimientos, con la plena pretensión de que adquiera lo necesario para poder ser miembro de la sociedad, para poderse incorporar y responder en la misma medida que esta le impone; de lo contrario será excluido, rechazado, visto como un extraño, recluido, confinado al olvido, a la esquina más profunda del salón.

El problema de la educación con cada generación, es precisamente quedarse allí, lo cual sucede porque quienes enseñan son de otras generaciones ya encadenadas a sus marcos referenciales, a sus marcos morales, la voluntad ya ha sido domada y desde allí se imponen al Otro, quieren adoctrinarle, mientras el Otro busca su emancipación, su apertura, se resiste a ser encadenado de la misma manera que sus maestros a ser convertido en uno más. 
Por ello, para que la educación trascienda se requiere que el mismo maestro se evada de sí mismo, de sus encuadres morales, se desestabilice, que rompa con sus propias cadenas para excederse, para descubrir nuevos lenguajes, para ir en busca del Otro por compasión y no esperar que él busque mi piedad (Mèlich, 2014, 2010b).

A partir de allí, la educación deja de ser transmisionista y el conocimiento ya no es el centro de todo acto educativo, se transforma, muda hacia una educación como excedencia, una educación que descubre lenguajes, formas de expresiones, saberes excepcionales, da cabida a la duda, a la incertidumbre y no encuentra una única respuesta cual verdad absoluta, sino respuestas múltiples desde donde cada sujeto, a partir de sus propias perspectivas, aporta a la construcción de nuevos saberes.

Una educación ética encuentra en el otro posibilidades, no imposición de esquemas de referencia, se abre a la epifanía del rostro del Otro, se presenta contemplativo ante él para aprender de él; así los roles entre maestro y estudiante se diluyen y ambos son maestros y aprendices, ambos tienen algo que compartir, algo que donar al Otro, algo que dar al Otro. ${ }^{12}$

Así, la educación logra en cabeza de sus actores, trascender, ir más allá, generar un escenario de contingencia para el acontecimiento ético (Bárcena y Mèlich, 2000, 2014) en el cual, cada quien es responsable del Otro, donde ninguno está en mejor posición que el Otro; por el contrario, donde todos nos construimos en la relación con el Otro y con el conocimiento. Desde este punto de vista, se transita de una educación moral, de dominación, de control y adoctrinamiento, a una educación ética, de contingencia, de incertidumbre, donde la duda es curiosidad no desconfianza y la interpelación no es irrespeto sino escucha, eso que para Han (2017) significa:

Escuchar no es un acto pasivo. Se caracteriza por una actividad peculiar. Primero tengo que dar la bienvenida al otro, es decir, tengo que afirmar al otro en su alteridad. Luego atiendo a lo que dice. Escuchar es un prestar, un dar, un don. Es lo único que le ayuda al otro a hablar. No sigue pasivamente el discurso del otro. En cierto sentido, la escucha antecede al habla. Escuchar es lo único que hace que el otro hable. Yo ya escucho antes de que el otro hable, o escucho para que el otro hable. La escucha invita al otro a hablar, liberándolo para su alteridad (pp. 117-118).

Así mismo, responsabilidad por el Otro, por su palabra. La educación entonces, se podría entender como escenario ético, de encuentro en procura de propiciar la formación del Otro. Formación que se presenta en el cara-a-cara, en la escucha atenta a lo que el Otro quiere decir y que se le ha negado a toda costa. Se asiste, a una educación que supera el adoctrinamiento y se presenta como diálogo, apertura y encuentro.

\section{Sobre la condición de humanidad: la corporeidad 13 como nicho de la existencia propia y compartida}

Esta perspectiva ética parte de asumir cómo se han expresado las relaciones existentes entre el ser humano finito y corpóreo con la presencia/ ausencia del otro y la respuesta otorgada desde lo educativo, o sea, una respuesta que nunca lo es completamente porque al frente se encuentra el Otro, es decir, a partir de los procesos de encuentro y aparición del otro ante el sí mismo, aparición que ocurre con la llegada del cuerpo, ese que es corporeidad da paso al acontecimiento, a las transformaciones, a las posibilidades de llegar a ser, en términos del mismo Mèlich (2010a, p. 11)

El cuerpo es, mientras que la corporeidad llega a ser y, a la vez, llega a ser otra de lo que es, llega a ser distinta, llega a ser contra lo que es... y, también, nunca es del todo, porque un ser corpóreo remite a un escenario abierto, siempre móvil, un escenario que no puede eludir el pasado, el recuerdo de lo que ha sido, de lo que le han hecho, la herencia recibida, la gramática en la 
que ha sido educado y, al mismo tiempo, remite a un porvenir, no solamente a un futuro más o menos previsible, programable o planificable, sino a un porvenir que siempre está por venir, que siempre está abierto a los acontecimientos que rompen cualquier proyecto, cualquier identidad, cualquier fijación.

Eso que somos como corporeidad y que llegamos a ser, es lo que con la ayuda de la educación nos vamos haciendo, nos vamos transformando y vamos transitando por nuestra propia existencia sin quedarnos en ella, sin detenernos en nuestro propio cuerpo, sino lanzándonos hacia el Otro, arrojándonos más allá del ser, incluso de-otro-modo-que-ser (Lévinas, 1987).

El ser humano es corpóreo, es decir, un ser de carne y hueso, un ser que habita un lugar en el mundo desde su existencia y al mismo tiempo es habitado por múltiples dimensiones que reposan sobre su existir corpóreo como posibilidad, el lenguaje, el pensamiento, la sensibilidad, las funciones biológicas y orgánicas así como las construidas socialmente tienen razón de ser en la corporeidad, esa que nos hace ser humanos. Este escenario de corporeidad constituido por lo visible y por lo invisible, por lo inmanente y lo quiasmático o por la unión del alma y el cuerpo (Merleau-Ponty, 1993, 2006) son los que posibilitan la existencia humana propia, particular, singular y complementariamente compartida con los otros y con el mundo.

Esta condición de existencia en la corporeidad y desde la corporeidad nos hace asumir una posición en la que el ser humano es un ser encarnado, un ser que no sólo tiene carne o cuerpo, sino que es carne y es más que cuerpo (corporeidad); en términos de Henry (2001).

Los seres encarnados son seres sufrientes, atravesados por el deseo y el temor, que sienten toda la serie de impresiones vinculadas a la carne por cuanto que, constitutivas de su sustancia una sustancia impresional por tanto-, comienzan $y$ acaban con lo que ella experimentan ( $p .11$ )

Eso que nos atraviesa como humanos, que nos toca y nos trastoca va rompiendo poco a poco lo que creíamos ser, saber o conocer, va mostrando nuestra frágil y vulnerable condición expuesta siempre a lo imprevisto, a lo que viene de lejos y de afuera, a lo que se escapa de nuestro control y que se convierte en condición de posibilidad para entrar en relación y encuentro con el Otro y con lo otro, esas tenues certezas de lo que uno es o cree haber sido van desbordándose hacia lo nuevo y lo desconocido, hacia el Otro.

Podría decirse entonces que la corporeidad encarnada es más que la objetividad del cuerpo cosa o cosificado, es un cuerpo que toca y es tocado, que desea y es deseado, un cuerpo como corporeidad sintiente con gestos llenos de significados (Vanegas, 2001), una corporeidad que se construye socialmente (Le Bretón, 2000) en el marco de las relaciones que se tejen con los demás, con los prójimos más cercanos, incluso con los extraños y los extranjeros.

Justamente, el reconocimiento del Otro de sí mismo como lo plantea Mèlich (2010a), o sea, del cuerpo como corporeidad, implica una respuesta adecuada o inadecuada a la solicitud del Otro, respuestas que son constantes en los procesos de formación y que en ocasiones limitan, rechazan o invisibilizan la existencia del otro en la Escuela, en las instituciones sociales construidas y que construyen la humanidad; sin embargo, una respuesta ética (al menos desde la perspectiva Lévinasiana) fundará su expresión en la escucha, en el lenguaje, en la obediencia al mandato del rostro del Otro (Lévinas, 2001a) y a la posibilidad de elegir responsablemente como permitir que el Otro siga siendo, como acompañar su proceso de llegar a ser, como llegar a ser juntos, entre nosotros (Lévinas, 2001b) manteniendo una distancia próxima, una relación cercana sin absorber la existencia del otro, sin eliminarla sutilmente en la homogeneidad ni abruptamente en la total heterogeneidad.

El cuerpo como corporeidad no nace, sino que se hace, no está previsto, programado o determinado, sino que es puro inacabamiento, incertidumbre, vértigo, es apertura del hombre al mundo, es riesgo atravesado por el encuentro y la 
aparición de los otros en la propia existencia, es la sensibilidad que irrumpe e interpela la propia calma, es el gozo de sentirse vivo, afectación que viene de afuera a increpar la propia piel, petición de otro que yace expuesto y manda, ordena, clama, llama preocupación, atención y recibimiento. Con razón insistió Unamuno (1913): "Ni lo humano ni la humanidad, ni el adjetivo simple, ni el sustantivado, sino el sustantivo concreto: el hombre. El hombre de carne y hueso, el que nace, sufre y muere -sobre todo muere-, el que come y bebe y juega y duerme y piensa $y$ quiere, el hombre que se ve y a quien se oye, el hermano, el verdadero hermano" (p. 3); si, el hermano, quien no tiene su propio cuerpo, sino que sufre y vive y muere en su cuerpo.

\section{Notas}

1 Se hace necesario precisar la diferencia entre "otro" y "Otro"; el "otro" es otro objetualizado, cosificado y anclado a una gramática (Mèlich, 2014) que lo clasifica y lo categoriza desconociendo así su radical alteridad. Por su parte el "Otro" es lo absolutamente otro, es aquel que rompe todo mis esquemas y que me altera en mi propia esencia, es quien nunca podré llegar a ser y, parafraseando a Lévinas (2009, p. 133) exige de mí responsabilidad sin que él se haga responsable de mí.

2 En un artículo que lleva este nombre, se expresan las diferencias considerables entre hablar del otro y hablar con el otro, la primera referida a una forma de definir y tematizar al otro y la segunda, como posibilidad para que surja la relacionalidad y el encuentro. Ver: Jaramillo y Orozco (2015) y Jaramillo y Murcia (2014).

3 Mèlich (2014) prefiere utilizar el término "ser finito".

4 Mèlich (2014) en su obra Lógica de la crueldad, desarrolla el concepto de gramática para plantear que vivimos una realidad moral en la que todo está controlado, predeterminado, donde todo ya ha sido nombrado y cuenta con un significado.

5 Sobre este asunto, Zielinski (2011) muestra con suficiente elocuencia el planteamiento de Lévinas acerca de la responsabilidad, esa que es sin porqué, sin contrato, sin reciprocidad.

6 Para Lévinas, el "Infinito" es la humanidad en el Otro, que demanda una respuesta ética de mí, lo que implica una respuesta no predeterminada, no de libreto ni de manual como la da la moral, sino una respuesta contingente ante la contingencia de la aparición, presencia e irrupción del Otro.

7 Para Lévinas es el conocimiento como ya se había mencionado; en cambio es más conveniente emplear el término gramática de Mèlich, mucho más cercano al mundo propiamente.

8 Desde esta perspectiva se desarrolla una amplia crítica a las políticas y apuestas por la inclusión, pues incluir al Otro, es normalizarlo, es hacerlo otro más. Por tanto, diría Mèlich que la inclusión en tanto gramática moral incluye también la exclusión de aquellos que no cumplen los requisitos necesarios para ser incluidos o clasificados; este es uno de tantos ejemplos de lo que él denomina lógica de la crueldad.

9 Dice Viveros y Vergara (2014) que la distancia con el otro está asociada a la otredad, mientras que la proximidad y la cercanía dan cuenta de la alteridad.

10 Necesidad, no como ausencia de algo que nos falte sino, como desbordamiento por exceso de algo. Ver por ejemplo Domínguez (2005) y Leibovici (2012)

11 Al mejor estilo de la "educación bancaria" ya denunciada por Freire (2005) en su Pedagogía del Oprimido.

12 Lévinas (1977, p. 263) plantea que esta entrega “... consiste, para el uno, en dar el mundo, su posesión, al otro...". Así mismo, Skliar (2007a, 2007b y 2011 ; y en colaboración con Larrosa (2009) insiste en una educación que es del Otro, que se da con el Otro y es para el Otro.

13 La corporeidad tiene sus raíces en la fenomenología, principalmente en los desarrollos de la fenomenología de la percepción de Merleau-Ponty (1993) y se asocia estrechamente con lo expuesto por Duch y Mèlich en escenarios de la corporeidad (2012); en estos textos, así como en otras referencias tratadas en este documento, se sostiene la condición humana desde sus dimensiones sintientes, vivientes y por supuesto, corpóreas.

\section{Referencias bibliográficas}

Bárcena, F., \& Mèlich, J-C. (2000). La educación como acontecimiento ético. Barcelona: Ediciones Paidós.

Bárcena, F., \& Mèlich, J-C. (2014). La educación como acontecimiento ético: Natalidad, narración y hospitalidad. Buenos Aires: Miño y Dávila editores. Segunda edición revisada y aumentada.

Domínguez, J. E. (2005). El concepto de excedencia en las obras de Emmanuel Lévinas anteriores a totalidad e infinito 1934 a 1954. México: Universidad Autónoma de México. Recuperado de https://bit.ly/2DRWFPT

Duch, L., \& Mèlich, J.C. (2012). Escenarios de la corporeidad. Antropología de la vida cotidiana 2. Madrid: Editorial Trotta.

Freire, P. (2005). Pedagogía del Oprimido. México: Siglo XXI Editores S.A. de C.V. Trad. Jorge Mellado.

Han, B-Ch. (2012). La sociedad del cansancio. Barcelona: Herder Editorial.

Han, B-Ch. (2014). La agonía del Eros. Barcelona: Herder Editorial. 
Han, B-Ch. (2017). La expulsión de lo distinto. Barcelona: Herder Editorial.

Henry, M. (2001). Encarnación, una filosofía de la carne. Salamanca: Ediciones Sígueme.

Jaramillo, D. A., \& Orozco, M. (2015). ¿Hablar del otro o hablar con el otro en educación? Revista Latinoamericana de Estudios Educativos, 11(2), 47-68.

Jaramillo Ocampo, D. \& Murcia Peña, N. (2014). Hacia una pedagogía del encuentro: apuestas por la relación cuerpo-alteridad en educación. Revista de Investigaciones UCM, 14(24), 142-149.

Le Bretón, D. (2000). El cuerpo y la educación. Revista Complutense de Educación, 11(2), 35-42.

Leibovici, M. (2012). Claustrofobia de sí y necesidad de excedencia. La "Patética del Liberalismo" según Emmanuel Lévinas. Santiago de Chile: Revista de la Academia, 17, 21-31.

Lévinas, E. (1977). Totalidad e infinito, ensayo sobre la exterioridad. Salamanca: Ediciones Sígueme.

Lévinas, E. (1987). De otro modo que ser o más allá de la esencia. Salamanca: Ediciones Sígueme.

Lévinas, E. (2001a). La realidad y su sombra. Libertad $y$ mandato. Madrid: Editorial Trotta. S.A. Traducción de Antonio Domínguez Leiva.

Lévinas, E. (2001b). Entre nosotros, ensayos para pensar en otro. Valencia: Editorial Pre-textos.

Lévinas, E. (2006). De la existencia al existente. Madrid: Arena Libros. Traducción de Patricio Peñalver.

Lévinas, E. (2009). Humanismo del Otro hombre. Madrid: Siglo XXI editores.

Lévinas, E. (2011). De la evasión. Madrid: Arena Libros. Segunda Edición. Trad. Isidro Herrera.

Lévinas, E. (2012). Totalidad e infinito. Ensayo sobre la exterioridad. Salamanca: Ediciones Sígueme, 2da Edición. Traducción de Miguel GarcíaBaró.

Mèlich, J. C. (2010a). El otro de sí mismo. Por una ética desde el cuerpo. Barcelona: Editorial UOC.
Mèlich, J. C. (2010b). Ética de la compasión. Barcelona: Herder Editorial.

Mèlich, J. C. (2014). Lógica de la crueldad. Barcelona: Herder.

Merleau- Ponty, M. (1993). Fenomenología de la percepción. Barcelona: Editorial Planeta.

Merleau- Ponty, M. (2006). La unión del alma y el cuerpo, Malebranche, Biran y Bergson. Madrid: Ediciones Encuentro.

Murcia, P. N. (2012). La escuela como imaginario social. Apuntes para una escuela dinámica. Magistro 6(12), 53-70. Universidad Santo Tomás.

Skliar, C. (2007a). La educación (que es) del otro: argumentos y desiertos de argumentos pedagógicos, 1 ed. Buenos Aires: Ediciones Novedades Educativas.

Skliar, C. (2007b). ¿Y si el otro no estuviera ahí? notas para una pedagogía (improbable) de la diferencia. Buenos Aires: Miño y Dávila.

Skliar, C. (2011). Lo dicho, lo escrito, lo ignorado. Escritos mínimos entre educación, filosofía $y$ literatura. Buenos Aires: Miño y Dávila Editores.

Skliar, C., \& Larrosa, J. (2009). Experiencia y alteridad en educación, 1 edición. Rosario: Homo Sapiens Ediciones.

Unamuno, M. (1913). Del sentimiento trágico de la vida. Salamanca: El Adivinario.

Vanegas, J. H. (2001). El cuerpo a la luz de la fenomenología. Manizales: Artes gráficas Tizán y Universidad Autónoma de Manizales.

Viveros, E.F., \& Vergara, C.E. (2014). Aproximación a la noción de encuentro en Emmanuel Lévinas. Revista Virtual Universidad Católica del Norte, 41, 61-69, febrero-abril. Fundación universitaria Católica del Norte, Medellín. Recuperado de https://goo.gl/qN232j

Zielinski, A. (2011). Lévinas: la responsabilidad es sin porqué. Bogotá: Universidad Externado de Colombia. Traducida por Alberto Supelano. 